\title{
KNOWLEDGE TOOLS IN SMEs: A ROMANIAN OVERVIEW
}

\author{
Eduard Gabriel CEPTUREANU \\ University of Economic Studies, Management Dpt., Bucharest, Romania \\ eduard.ceptureanu@man.ase.ro
}

\begin{abstract}
For knowledge management, just like for any other science, methods and techniques used in various knowledge processes are essential. However, despite an abundant literature dedicated to knowledge management, knowledge tools are still a poor charted area. Contributions in this area has several specialists: Kazi , in terms of systematization of knowldege tools, Samii in designing new KM tools, Meir Russ or Swartz in integrating KM tools with organizational and strategy setting. This paper presents the results of an empirical study on Romanian companies, most of them SMEs, aimed to provide an overview on knowledge tools in terms of the reasons to implement them, of the advantages and problems encountered during their use or the knowledge activities they are most suitable for. This is one of the first studies in Romania and provides some useful insights on one of the most dynamic but least represented parts of knowledge management.
\end{abstract}

\section{Keywords: knowledge, management, knowledge tools, small and medium enterprises}

\section{Introduction}

Historically, Knowledge Management focused on larger organizations, little importance being paid to small and medium enterprises (SMEs) [1]. This is rather unusual, as SMEs are a key economic segment in any developed economy.

\section{Literature survey}

Compared with other managerial tools, knowledge based tools have several features [2], [3], among which we mention:

a) adaptation of an important part of classic managerial tools to the specificity of knowledge through consistent and functional changes [4], [5];

b) predominance of IT-based tools of knowledge management, most with rather simple methodological construction;

c) increase in implementation of virtual KM tools;

d) proliferation of management methods and techniques that made connections, communication and cooperation between people (entrepreneurs, staff) on different geographical locations and at considerable distance from each other possible;

e) there is evidence that there are large differences in results using similar KM tools because of the strong dependence of knowledge, skills and motivation of entrepreneurs and specialists involved;

f) most KM methods and techniques used by SMEs are very heterogeneously implemented due to high innovative capacity of entrepreneurs and different organizational contexts;

g) the most intense and effective use of management tools knowledge is recorded in small and medium sized organizations with a significantly lower proportion in very small SMEs;

h) KM tools have a strong human dimension, whose treatment involves flexibility and diversity. 
Contributions in this area has several other specialists: Kazi [6], in terms of the systematization of knowldege tools, Samii [7] in designing new KM tools, Meir Russ [8] or Swartz [9] in integrating the KM tools with organizational and strategy setting.

Another approach of KM-based tools links them with $\mathrm{KM}$ initiatives and models. For instance, Natorojan established a general framework for KM, explicitly stating the role of several KM tools in the implementation of his model [10], while Miller emphasized the need to adapt KM tools to types of task rather than to size of the enterprise [11]. Finally, the last theoretical approach trend in KM tools area focused on providing companies with integrated tools from which any manager, entrepreneur or staff to choose the most appropriate ones [12] according to their needs.

Irma Becerra-Fernandez

divides specific knowledge management tools into four categories:

- Knowledge storage systems that store and formalize the expert knowledge, so that they can be shared with other specialists. They record the tacit knowledge of experts and present it systematized in certain forms, such as maps of knowledge;

- Knowledge use systems that select and retain their knowledge for reuse in solving recurring and new problems. This category includes general pattern of knowledge management, community-based expert knowledge, expert systems, teleconferencing, etc.

- Knowledge discovery systems that create new knowledge by implementing intelligent algorithms. This category includes transducers, investigation techniques (mining) in databases and information, etc.;

- Knowledge directories, which organize and disseminate knowledge. An example of such a method is the localization of knowledge systems.

\section{Research}

\subsection{The sample}

Based on how old are the analysed companies, most of them have less than 5 years old (roughly 40\%), followed by enterprises aged between 5-10 years (almost $30 \%$ ), while well established companies ( $>$ 10 years) represent the rest.

Distribution of the sample by location shows that the best represented region is Bucharest (roughly 30\%), followed by West and Central regions, while the poorest represented is the North East reagion, with less than $5 \%$ of the sample.

According to size, most part of the sample is represented by small and medium sized companies (almost two thirds of the total), micro companies representing slightly higher than $20 \%$; roughly $10 \%$ of the investigated companies are LSEs.

Considering the legal form, there is a balance between limited liability and corporation types, while other legal forms are negligible with less than $3 \%$.

Considering industries in which those companies operate, the structure is as follows: almost $20 \%$ of companies are operating in pharmaceutical industry, more than $20 \%$ operate in consultancy, more than $20 \%$ are in general services, almost $30 \%$ offer financial services, while the rest operates in tourism, transport and manufacturing.

By ownership, all companies are private owned.

\subsection{Research results}

Among the factors which determined the ownership of SMEs to implement knowledge management tools, respondents emphasized, in this order, improve efficiency and requirements of consultants (combined almost $75 \%$ of all answers), while the know-how transfer from partners or lack of results from traditional management tools were less considered.

Regarding the owners/managers' perception on knowledge management 
tools, in almost $40 \%$ of the cases they consider them important and are fully supportive, almost $30 \%$ are aware of them but find difficult to support, almost $25 \%$ provided initial support but become disillusioned, while slightly more than $10 \%$ consider them as unimportant.

Regarding employees' perception on knowledge management tools, there is an evident difference compared to managers. For instance, more than $50 \%$ are not interested in their implementation or are not ready to get involved, while slightly above $20 \%$ consider them important and are willing to provide full support.

Among the challenges in implementing the $\mathrm{KM}$ tools, the most problematic was that of finding and hiring knowledge specialists and accountability of resources for owners while lack of commitment from top executives.

Among advantages in implementing the KM tools, their implementation has generated new sources of competitive advantage or increased turnover, while improvement in managing intellectual property rights was the least cited of all.

In terms of the knowledge activities, managers used the KM tools in order to develop the networking with suppliers or knowledge generators and to develop the networking with customers and end-users while the innovative side, like developing new internal processes or developing new knowledge based products or services is poorly represented.

Concerning the general perception of the Romanian entrepreneurs or managers on knowledge management tools results, the majority of respondents said they appreciate them (more than 90\%) while only a minority were disappointed.

Regarding the main learning approach in implementing the KM tools, most surveyed companies used traditional trainings or previous experience, while intra-organizational knowledge transfer or good practices transfer from other companies are less cited.
Regarding the types of knowledge that these tools focus on, know-what and know-how knowledge are emphasized, while know-who knowledge is in minority of SMEs.

\section{Conclusions}

The knowledge management tools representation in literature is still poor due to their novelty and still low use by companies [14]. Significant use of traditional management methods and techniques is recorded because of reluctance of managers in implementing new systems and their related costs [15]. Additionally, many knowledge tools are still based on or require integration with traditional management tools, making them even more prone to rejection by companies [16].

Specific knowledge management tools implementation is often more difficult to implement because they have a strong IT component [17]. Furthermore, a considerable part of the knowledge management instruments rely partially or totally on technologies subject to patents, copyrights, etc. Finally, the actual use of them requires high skilled employees, the so called knowledge workers, and companies can afford only small proportions of these employees [18].

All these issues may favour, however, the implementation of knowledge tools in SMEs. Their flexibility and the desire to innovate, to reduce resistance, to change make it possible for them to fully implement knowledge tools and techniques. Furthermore, their localization in industries prone to knowledge - the so called knowledge industries - is an even more facilitator.

For Romania, several things arise from the exploratory research. First of all, the main determinants of knowledge management tools use rather external facilitators.

Top executives have a significant higher favourable attitude towards the knowledge management tools than 
employees, possible due to a poor communication or an unfavourable organizational culture.

Among the challenges in implementing the $\mathrm{KM}$ tools, the most significant one was the finding and hiring knowledge specialists, while among the advantages, the most common ones are new sources of competitive advantage or increased turnover.
In terms of the knowledge activities, the KM tools were predominantly used to develop networking with knowledge suppliers or generators or with customers and end users of products or services while the innovative side - introducing new processes or developing new products or services based on knowledge, is less common.

\section{References}

[1] Delahaye, B.L., Human Resource Development and the Management of Knowledge Capital, Human Resource Management: Challenges and Future Directions. Brisbane: John Wiley \& Sons Australia, 2003

[2] Ruggles, R., Knowledge Management Tools. Taylor \& Francis, 1997

[3] Nicolescu, O. and Nicolescu, C., Organizatia si managementul bazate pe cunostinte, Bucharest, ProUniversitaria, 2011

[4] Ceptureanu E.G., Employee's reaction to change in Romanian SMEs, Review of International Comparative Management, Vol. 16, No. 1, pp.77-87, 2015

[5] Ceptureanu E.G., Research regarding change management tools on EU SMEs, Business Excellence and Management Review, Vol.5, No. 2, pp.28-32, 2015

[6] Kazi, S., Wohlfart, L., Wolf, P. Hands on knowledge co-creation and sharing: Practical Methods and Techniques. Stuttgard: Knowledge Board, 2007

[7] Samii, R., Knowledge Management and Learning Tools and Technique. Version 3, 2007

[8] Russ, M., Knowledge Management Strategies for Business Development. Hershey: Business Science Reference, 2010

[9] Swartz, D., Encyclopaedia of Knowledge Management. London: Ideea Group Reference, 2006

[10] Natorojan, G., A KM Maturity Model for the Software Industry. Knowledge Management Review, Vol. 8, No.1, pp.12-19, 2005

[11] Miller, R., Model-Driven Projects in Chemical Industry. Knowledge Management Review, Vol. 7, No.3, pp. 23-34, 2006

[12] Laurie, D.; Doz, Y.; Sheer, C., Creating New Growth Platforms. Harvard Business Review, Vol. 5, pp. 55-68., 2006

[13] Bacerro-Fernandez I., Locating Expertise at NASA, Knowledge Management Review, Vol. 4, No.4, 2001

[14] Ceptureanu S.I., Knowledge management in Romanian young SMEs, Review of International Comparative Management, Vol.16, No.1, pp.5-22, 2015

[15] Ceptureanu S.I. and Ceptureanu E.G., Knowledge management in Romanian companies, Quality-Access to success, Vol. 16, No.145, pp.61-66, 2015

[16] Ceptureanu SI, Ceptureanu EG, Tudorache A. and Zgubea F., Knowledge based economy assessment in Romania, Economia. Seria Management, Vol. 15, No. 1, pp.70-87, 2012

[17] Ceptureanu E.G. and Ceptureanu S.I., Change management survey on innovative ITC Romanian SMEs, Quality-Access to success, Vol. 16, No.144, pp.62-65, 2014

[18] Ceptureanu S.I., Knowledge based economy in Romania: comparative approach, Journal of Applied Quantitative Methods, Vol. 9, No.4, pp.51-61, 2014 